OPEN ACCESS

Edited by:

Grit Höppner,

Catholic University of Applied Sciences, Münster, Germany

Reviewed by:

Mattias Kärrholm, Lund University, Sweden André Heitmann-Möller, Ostfalia University of Applied Sciences, Germany

*Correspondence: Vera Gallist vera.maria.gallist/@univie.ac.at

Specialty section: This article was submitted to Sociological Theory, a section of the journal

Frontiers in Sociology

Received: 30 November 2017 Accepted: 09 April 2018 Published: 25 April 2018

Citation: Wanka A and Gallistl V (2018) Doing Age in a Digitized World - A Material Praxeology of Aging With Technology. Front. Sociol. 3:6. doi: 10.3389/fsoc.2018.00006

\section{Doing Age in a Digitized World-A Material Praxeology of Aging With Technology}

\author{
Anna Wanka ${ }^{1}$ and Vera Gallist ${ }^{2 *}$ \\ ${ }^{1}$ Department of Social Pedagogy and Adult Education, Goethe University, Frankfurt, Germany, ${ }^{2}$ Department of Sociology, \\ University of Vienna, Vienna, Austria
}

Digital technologies have gained vast relevance in postmodern societies and digital infrastructures are substantially integrated into the everyday lives of older people. This digitization is reframing the norms and practices of later life as well as the social construct of age itself. Despite the increasing amount of studies in the field of aging and technologies, it still lacks theorizing. This paper addresses this deficit, suggesting that the study of aging and technologies could profit from a comprehensive integration of theories from the sociology of aging, critical gerontology, and science-and-technology studies. We aim to make a theoretical contribution to this issue, asking: how is age being done in a digitized world? Applying a praxeological approach to aging and technologies, we firstly examine how theoretical and empirical work has constructed aging with technologies so far and identify its shortcomings. Some of this work so far lacks a proper consideration of social inequalities within these processes, whereas other studies lack a thorough consideration of materialities. Secondly, in an attempt to equally "praxeologize" and "materialize" the study of aging and technologies we develop a theoretical model that aims to overcome these shortcomings. In what we frame as a material praxeology of aging with technology, we are concerned with how age is being done through discursive formations, set into practice through social and material practices and involved in the (re)production of social inequalities. Enriching a Bordieuan terminology of social fields with notions of non-human agency, this praxeology is founded on three assumptions: (1) Social fields constitute the contexts in which age as a social phenomenon is being done with and through technologies (2) Human and non-human agents are equally involved in this process (3) The actions of the involved agents emerge from an agency distributed among them, and are structured through the power relations between them. Thirdly, we exemplify the application of this model by reference to a research project in the field of Active and Assistive Living.

Keywords: doing age, technologies, practice theories, materialism, aging

\section{INTRODUCTION}

The societal and scientific understanding of age has changed. Once viewed as a biologically determined status, later life is increasingly understood as a stage of life that is open to change. In sociology, old age is seen as a social construct that has evolved historically and differs from society to society. Recent work in critical gerontology has consequently shown 
how age is being done through various social practices, but also posed the question how age and aging are co-produced in and through materialities.

One contemporary area of research that is particularly fruitful in studying the materialities of aging is the field of aging and technologies. Digital technologies have gained vast relevance in postmodern societies and digital infrastructures (comprised of, for example, smartphones, tablets, PCs, apps, fitness trackers, and many other digital devices) are substantially integrated into the everyday lives of older people. Despite the fact that older adults are often framed as "laggards" in the innovation process (Beal and Bohlen, 1957), they have become one major target group for technology development and research, particularly in the field of medical and assistive technologies (Rosales and Fernández-Ardèvol, 2016). This digitization is currently reframing the norms and practices of later life (Marshall and Katz, 2016), and hence coproducing the social construct of age itself. Despite the increasing amount of studies in the field of aging and technologies, it still lacks theorizing (Sixsmith and Gutman, 2013).

This paper addresses this deficit, suggesting that the study of aging and technologies could profit from a comprehensive integration of theories from the sociology of aging and science-and-technology studies (STS). We aim to make a theoretical contribution to this issue, asking: how is age being done in a digitized world? Which elements constitute the doings of age with technologies?

To approach these questions, we will take three steps: in the first section, we examine how theoretical and empirical work in the field of technologies and aging has constructed age with technologies so far. In the second part, we present a theoretical model which aims to further theorize the doings of age with technologies. In an attempt to equally "praxeologize" and "materialize" the study of aging and technologies, we will bring together core concepts of Pierre Bourdieu's praxeology (1977) with concepts of STS. In the third section, we exemplify the application of the proposed model by reference to a research project in the field of Active and Assistive Living (AAL). Finally, we conclude by discussing the implications and limitations of this approach and provide an outlook for further research.

\section{CONSTRUCTING AGE IN SOCIOLOGY, GERONTOLOGY, AND STS}

In this section, we discuss how empirical and theoretical work on the topic of aging and technologies has constructed aging so far. To do so, we regard approaches from three paradigms that have been most influential in studying aging and technologies in the past: rational choice theories, structural-institutional theories and post-structural theories. As most of the recent studies on aging and technologies fall under the latter, we focus on the different perspectives it comprises-cultural and practice theories as well as approaches from STS. In each section, we provide an overview about the most commonly used concepts in this field, explain how they have been used to conceptualize aging and discuss which elements of the doings of age they might emphasize.

\section{Rational Choice Theories: Technology Acceptance in Later Life}

Theories within the rational choice paradigm are centered on the explanans of individual choice that can be framed as rational. Rationality-in this approach-presupposes an accurate cost-benefit-analysis, but also depends upon individual preferences, beliefs, and constraints (Wittek et al., 2013).

Rational choice theories have been widely used to explain the differences in uptake of technologies by different social groups. One of the most wide-spread models is the Technology Acceptance Model (TAM), originally developed by Davis (1989) and developed further by him and colleagues (Davis and Venkatesh, 1996; Venkatesh and Bala, 2008). The model portrays a modification of (Ajzen and Fishbein, 1980) theory of reasoned and aims to explain the intention to use a technology with rational reasoning. A vast body of empirical literature shows that TAM explains a substantial percentage of variance (around 40\%) in the intention to use a technology. The model hypothesis claims that this intention is determined by (1) its subjectively perceived usefulness (evaluation of outcomes) and (2) its subjectively perceived level of difficulty (constraints; Davis and Venkatesh, 1996). Hence, the less useful a technology is to an individual and the more they would have to invest in learning to use it, the less likely they are to use this technology.

The model is also widely used in the sociology of aging to explain technology acceptance in older adults, and systematic reviews show that it explains a great amount of variance in technology use of older adults as well (Niehaves and Plattfaut, 2013). Peral-Peral et al. (2015) even go so far as to speak of a "psycho-digital divide" (p. 57), arguing that preferences, beliefs and perceived constraints explain more about technology acceptance than socio-structural variables like income or education (Seifert and Schelling, 2016).

Studies within this paradigm link the discussion on the technology uptake of older adults to questions around successful and active aging with new technologies. Numerous studies have shown positive correlations between internet use and subjective wellbeing (Choi et al., 2012; Forsman and Nordmyr, 2015; Damant et al., 2016), pointing to the fact that engagement in new technologies might be of importance for successful and active aging.

Rational choice theories have, however, become heavily criticized in sociology. Critics question their basic assumption about human behavior, which simplifies it to fit economic models and makes it too static (Kunemund and Tanschus, 2014). In their application of concepts like successful aging, this approach has also been criticized for its-more or less explicit-normative 
standards of what constitutes a good way of aging (Amann and Kolland, 2014), underestimating the influences of social structure on active aging as well as technology use.

Even though heavily criticized, rational-choice theories are the most commonly used approach to study technologies and aging in sociology and gerontology. This emphasizes how the construction of age in research is centered on ideas of active, successful, and healthy aging, and while many scholars have come to criticize all of these normative approaches, they still heavily influence the field in which research and development of technologies for older adults takes place.

\section{Structural-Institutional Theories: Technologies and Social Inequalities in Later Life}

Instead of ascribing differences in social phenomena to rational decisions, motivations and intentions of individuals, structuralinstitutional theories understand these differences as arising from social inequalities. Such inequalities are neither random nor individual, but based upon structural and/or institutional arrangements that induce unequal distributions of resources in a society (cf. Blau, 1977). Whereas structural sociology is often associated with researching income or educational inequalities, scholars have also been concerned with inequalities related to knowledge. Knowledge divide research argues that, despite seemingly increased overall access to information for the wider society, differences in (access to) knowledge increases social inequalities between status groups (Tichenor et al., 1970). While early research focused on media, it has, over time, incorporated digital technologies into its analyses and has framed the term "digital divide" (Zillien and Hargittai, 2009). The digital divide addresses the unequal distribution of opportunities to use technologies based on social traits-like age-which, in turn, leads to decreased chances in social participation (Selwyn, 2004).

This approach has contributed to the study of aging in that it has provided life-course perspectives on social inequalities and technology use. In his theory of "Cumulative Advantage/Disadvantage" (CAD), Dannefer (2003) argues that social inequalities cumulate over the life-course, leading to a polarization between social groups in old age. This hypothesis can also be applied to technology use: Silver (2013), for example, finds that it is not only socio-economic status in later life that affects Internet use in older adults, but also living conditions in childhood and early adulthood, and that these conditions accumulate and multiply in their effect on Internet usage.

From this perspective, inequalities in later life are the result of cumulative dis/advantage over the life-course, which is reinforced through institutions and legal arrangement of retirement (Walker, 1981), leaving older adults condemned to a life of passivity and socio-economic precarity (Riley et al., 1994). Estes (1979) concept of the "aging enterprise" is a tool for critically analyzing the organizations and careers created to serve-and hence define-aging and being old. It comprises

"[...] the programs, organizations, bureaucracies, interest groups, trade associations, providers, and professionals that serve elders in one capacity or another. Major components include physicians, hospitals, the Social Security Administration, the Administration on Aging, state and area agencies on aging, congressional committees on aging, and the nursing home and insurance industries" (ibid: 2).

Whereas throughout modernity, the aging enterprise framed the elderly as frail and dependent non-actors, this framing has changed in neoliberal societies. Major developments that have led to a change in policies for later life include the bio-medicalization and commodification of aging, as well as the privatization and rationalization of old-age policy (Estes, 1991). This has led to a state where, today, the needs of older adults are processed as a commodity that is sold for a profit (Estes, 2014).

Although Estes focuses in her own research on the medical industrial complex as an increasingly privatized and funded actor, others have applied her concept to technological developments. Joyce and Loe (2010), for example, lay out how the biomedicalization and commodification of aging is being conducted with and through technologies, pointing out how

"[...] individuals, academic centers, and businesses aim to create assisted living technologies and inclusive design projects so that older people can age at home. The focus in this market-based framework is on transforming technologies and architectural design to accommodate potential changes in hearing, memory, balance, sight, or other physical and cognitive abilities as well as creating technologies (e.g., robots, phones for the hearing impaired) to help meet emotional needs. The aging body is still enabled and constrained [...]." (ibid: 174)

From a political economy perspective, technologies for the old contribute to an ambivalent construction of age. The narrative used in the development of aging technologies is that later life is a potentially active and autonomous stage, but this potential can only be released by technological assistance. In the enterprise surrounding technological developments, older adults are, thus, equally addressed as rational consumers who are trusted to buy the best product, and beneficiaries that the technology will help and assist. This approach emphasizes age as constructed by political and economic actors and shows how the doings of age in neoliberal societies are be influenced through institutions, legal arrangements, businesses, and governments.

\section{Post-structural Theories: Knowledge, Practices, and Materialities of Aging The Cultural Turn: Discourses, Technologies, and Later Life}

The cultural turn, which has become widespread in sociology since the 1980s, has brought with it a shift of focus to meanings, symbols, knowledge, discourses, values, and beliefs that circulate in a society. Instead of focusing on individual intentions or manifested social norms, these authors share the notion that human action can be explained by

"[...] reconstructing the symbolic structures of knowledge which enable and constrain the agents to interpret the world according to certain forms, and to behave in corresponding ways. Social order then does not appear as a product of compliance of mutual 
normative expectations, but embedded in collective cognitive and symbolic structures, in a shared knowledge' which enables a socially shared way of ascribing meaning to the world." (Reckwitz, 2002: p. 245)

Critical cultural gerontology focuses on the modes of knowledge formation that serve to discipline and structure the experience of old age (Katz, 1996). Taking discourses and practices around successful aging as examples for their critical analysis, Katz and Marshall (2004) show how "functional" and "dysfunctional" has displaced the "normal" and "pathological" as the central biopolitical binarism of old age. The discursive formation of functionality and dysfunctionality in old age puts emphasis on the functional aging body and, subsequently, on the development of a functional aging self. From this perspective, old age appears as a discursive formation that is shaped by ideas surrounding health, functionality, and biologistic imperatives of aging well (Marshall and Katz, 2016).

The biosocial order organized around the functional/dysfunctional binary also provides a conceptual background for empirical studies on aging through and with technologies. Marshall and Katz, for example, explore how developments in self-tracking technologies create new modes of quantified aging (Marshall and Katz, 2016) and put emphasis on the ways in which age is quantified and standardized through technological devices. This approach also sheds light on technological mechanisms of self-enhancement, e.g., through brain training (Katz and Peters, 2008).

Empirical studies within this approach also draw attention to the policy discourses through which technology use in later life is regulated. Here, the "aging-and-innovation" discourse has been identified as a key rhetorical structure that legitimizes investments into technologies for older people. Within this discourse, population aging is conceptualized as a societal crisis, whereas the development of technologies appears to be the solution to the societal, economic, and individual problems that appear through aging (Neven and Peine, 2017).

\section{The Practice Turn: Doing Age With Technologies}

The practice turn followed the cultural turn in the social sciences. Similarly to cultural paradigms, practice theories are primarily concerned with knowledge-however, not discursive or textual knowledge, but implicit and incorporated knowledge and competence (Reckwitz, 2002) through which age is constructed in everyday life. Practice theories treat social practices as "the site of the social" (Schatzki, 2002), a "nexus of doings and sayings" (Schatzki, 1996) that is "a routinized type of behavior which consists of several elements interconnected to one other" (Reckwitz, 2002: 249), including bodily and mental activities, artifacts and things, knowledge, attitudes, and emotions. Age, from this perspective, is an ongoing social practice of interactive representations - it is something that people do, not something they are (Schröter, 2012).

Pierre Bourdieu's praxeology (1977) is one of the most influential practice theories. Central to his theory are the notions of habitus, capital, and the social "field" in which social practices and social constructions take place. Social fields are historically grown social spaces with specific distinct positions (Bourdieu, 1989). A field is, consequently, an arena in which social conflicts and battles on power relations are carried out, or, as Bourdieu puts it, a "locus of struggles" (Bourdieu, 1975: 19). Each field has its own "rules of the game" through which it functionsit entails norms, standardized processes and specific forms of knowledge that Bourdieu subsumes under the Greek term "doxa" for "common belief." The agents in the field must follow this doxa, i.e., believe in the rules of the field, which he calls "illusio." According to the field's doxa, agents occupy different social positions, depending on the volume and overall structure of their economic, cultural, social, and symbolic capital (Bourdieu, 1989). The position an agent occupies in a field defines and delimits its ability to act. Therefore, agency is always bound and dependent upon one's position within a field. Bourdieu (1977) emphasizes the dialectic relationship between structure and agency, which he explains to be manifested in the habitus.

The habitus can be described as an "ensemble of schemata of perception, thinking, feeling, evaluating, speaking and acting that structures all expressive, verbal, and practical manifestations and utterances of a person" (Krais, 1985: 169). It enables agents "to cope with unforeseen and ever-changing situations" (Bourdieu, 1977: 72) in a way that is in conformity with the agents' position in the field and the field logics. The habitus as the universe of practices of a group is the result of both power relations in the field and the specific field logics combined, but it is also able to change those power relations and field logics (Bourdieu and Passeron, 1990). Agents act intentionally without intentions (Bourdieu, 1990: 12) in accordance with the rules of the game and their relative position in the field, or as Wacquant (1989) puts it: "individuals make choices, but do not choose the principles of these choices" (p. 45).

Practice theories as inspired by Pierre Bourdieu have been widely used to explain technology use in later life. Schäffer (2003) describes how "medial practice cultures" vary across milieus and genders within one and the same generation, but results also hint to generational commonalities in media use among a generation (Pietraß and Schäffer, 2011). These studies, however, lack a proper consideration of the material elements of media practices. Even though practice theories have considered artifacts as matters of distinction, and the "bodily hexis" (Bourdieu, 1984) as part of the habitus, they do not grant those materialities a status apart from human use and are therefore not the center of these studies' empirical and theoretical attention. Theoretically, these studies struggle to conceptualize technologies as autonomous actors, even though materials are understood as inevitable and inseparable parts of the (human) habitus.

One concept that has been used to account for material aspects of the habitus is Bourdieu's habitat (Schmidt, 2008). The habitat and the habitus have been described as two different aggregate states of the social, with the habitat as an objectivized and accumulated form of social practice. In that sense, artifacts can be understood as "essential subsets of habitus" and as "organized forms of movements" (Sterne, 2003, 370). They incorporate institutionalized norms of how to use them, and hence are part of social practices. These practices are neither accidental nor easily modifiable and therefore shape the medial habitus. Technologies 
can then contribute to the agents' practices surrounding themeven more so, a technological artifact might call for a specific actor that is then created based on the habitat (Schmidt, 2006): using a tablet computer, e.g., might call for a human agent who possesses the relevant knowledge and skills to use it, but also for a specific self-image as a skilled and legitimate agent which might only be created through actually using the tablet computer. Based on these assumptions, technological artifacts are not granted autonomous agency. However, just like human actors, they are agential, as both are understood as participants of social practice.

More recent practice theories (Schatzki, 2002; Shove et al., 2012) have considered material elements in the doings of age more closely. They conceptualize social practices as "doings and sayings" (Schatzki, 1996), consisting of multiple elements which include bodily and mental activities, artifacts and things, knowledge, attitudes, and emotions. Neither persons nor technologies can initiate action on their own, but can become dynamic in social practices. From this perspective, people do not use technologies purposefully, but social practices follow teleoaffective structures (Schatzki, 2002). These structures are the "intentions" inherent to the different practices-for example, the practice of writing an e-mail aims to deliver a message in a specific interactional manner, and the involved persons and infrastructures (e.g., the mailing program) join in the "game."

More recently, authors have turned to using these practice theories to research technologies and aging. Kollewe et al. (2017), Endter (2016), and Depner (2015) for example all use ethnographic methods to describe how age is co-constructed with and through material practices and technologies in relation to the aging body. These studies, however, tend to lack a proper consideration of social stratification-differences between milieus, genders, or generations-and are therefore prone to ignore questions of power that are inherent in technology use.

\section{The Material Turn: The Materialities of Aging With Technologies}

The "material turn" emerged as a response to the focus of many discourse analysts on mental knowledge, language, and text; and to their neglect of materialized forms of knowledge. The field of STS was leading in this development.

What many STS-inspired approaches share is their assumption that all forms of knowledge-may they be explicit or implicit, discursive, or embodied-and particularly what we perceive as "nature" or "fact," are actually socially constructed (Knorr-Cetina, 1981). Starting with Knorr-Cetina's laboratory (Knorr-Cetina, 1981), research soon expanded from the social construction of scientific knowledge to the social construction of technologies, analyzing technological innovation, engineering, and design processes (Henderson, 1998; Helmreich, 2000; Forsythe, 2001).

The social construction of knowledge in these approaches is located within networks-for example, Callon's "assemblages," Derrida's "bricolage," Deleuze's "rhizome" or, in parts, Foucault's "dispositif" (apparatus). It is, however, Bruno Latour's ActorNetwork-Theory (ANT) that has gained particular prominence in the network-based study of knowledge production. In his "symmetric anthropology," he treats humans and nonhumans equally as things that act. Objects, things, nonhumans, technologies are capable of possessing agency, acting with humans in person-object networks. Agency, in terms of intentions, motivations or preferences, is from this perspective neither belonging to an individual, nor an attribute of a practice, but distributed across the network.

To better understand the pathways in which technology can act, STS has developed the concept of "scripts" (Akrich, 1992). Akrich describes how scripts, as possible scenarios of technology acting, are inscribed into technologies during the design and engineering process. In this process, projected users with specific abilities and preferences, as well as projected practices in which the technology shall be used, become part of a technology's material hexis (Bourdieu, 1984). For example, the washing machine was developed for a specific purpose-save time in doing the laundry-for technologically inexperienced housewives. The script, then, can be seen as similar to the motivation of a human or the teleo-affective structure of a practice. Similarly, a script only shapes the way a technology comes to participate in social practices and does not determine it. Particularly in regards to digital and smart technologies, the way the human-technology-interaction turns out is often not at all as imagined resp. scripted. De-scripting then addresses the scientific necessity to go back and forth between the projected and actual users and uses.

"In the context of AAL, this means to de-scribe how the subjectivity
of aged users is inscribed into AAL and, at the same time, how AAL
determines the subjectivity of aged users through the inscriptions."
(Endter, 2016, p. 137)

With this, STS has laid ground for what is today considered a post-humanist social theory:

\begin{abstract}
"Three ideas are combined variously by different authors in posthumanist theory: the hybrid assemblage of social and material elements in our world; the agency (Latour, 2005) or "performativity and power" (Pickering, 2005) of the material world, and finally, the resistances enacted by social and material phenomena in their interplay with each other." (Roosth and Silbe, 2009), pp. 14-15).
\end{abstract}

This post-humanist approach has been developed further by new materialism. New materialists criticize other approaches for not taking the notion of agential matter far enough. Humans, they claim, are still framed as more spontaneous and agential than socio-material artifacts, to which more inertia and stability is ascribed (Hirschauer, 2004). The "power of wonder" (Stengers, 2011) and idiosyncrasy that emerges from matter is usually overlooked. This asymmetry also becomes apparent in the different valuation between socially constructed artifacts, as "solidified social," and natural matter that might even elude practical accessibility (Folkers, 2013). In regards to technology use, this implies that one should not assume that technologies are-asymmetrically_ "used" by humans, but rather that they interact with them. 
Post-humanist theories and new materialism have developed closely alongside feminist STS. One of the early and more conspicuous essays was Donna Haraway's "A Cyborg Manifesto" Haraway's $(2013)^{1}$, in which boundaries between humans, animals and technologies are abolished. Gerontological theorists like Gilleard and Higgs (2015) draw on Harraway's distinction between the body as a social agent (as an element of the expression of personal identity through embodiment) and the body as a social actant (as the unmediated materiality of the body, where actions are realized without agency or intent in a sense of corporeality) to explain the embodied experience of later life. The experience of later life, they argue, is "conceived within a matrix of corporeality and embodiment" (ibid., 28) and out of this matrix arises a struggle between the embodiment of third age-e.g., through body work and anti-aging technologies-and the corporeal inevitability of the aging process.

This also draws attention to how differently subjective and bodily age is perceived and how temporality is materialized through bodies at different stages of the life-course. Third age, as a distinct stage of life is framed as a somatic culture (Williams et al., 2012) in which at least one purpose is to pursue intensive anti-aging strategies through the formation of the body. Ageas an embodied practice-is imagined as treatable or even avoidable through anti-aging technologies-opening up a gap between how old one person feels and how old their body actually is with regard to its function. In a new biologism of aging (Marshall and Katz, 2012), bodily aging appears more fluid and performative and hence opens up possibilities of new enhancement technologies.

Regarding aging and technologies, new materialism is taken up particularly in the field of health technologies, in which aging bodies and digital technologies are understood as co-producers of continuous materialization and hence the construction of age itself: doing age, here, is understood as an "interrelationship of societies and technologies" (Urban, 2017, p. 3).

For our theoretical reflections, post-structural theories emphasize the role of discursive formations in the construction of old age that are centered on ideas of functionality and dysfunctionality. Also, they show how these discourses are set into practice through socio-material arrangements and scripts.

\section{CONCLUSION}

This (admittedly summarized and thus most likely insufficient) overview of approaches that have been used to study aging and technologies emphasizes some common traits of current literature, as well as differences and topics for future theoretical development.

What all these approaches have in common is that they characterize certain aspects that are relevant in the doings of age with technologies. Rational-choice theories show how aging today is still focused on ideas of active and successful aging and

\footnotetext{
${ }^{1}$ Intended more as a metaphor to criticize mainstream feminism at the time it had a major impact on feminist STS studies and scholars who have since sought to "bring the material back into feminist theory and practice" (Alaimo and Hekman, 2008: 4) by defining a new relationship between discourse and matter.
}

how science and research draw on these ideas when studying aging with technologies. Structural-institutional theories bring the political and economic institutional arrangements through which old age is constructed today into discussion. Poststructural theories emphasize the role of norms and discourses around age and aging and show how they are set into practice through materialities in everyday life. Drawing on all of these theoretical approaches, we want to sketch out the field of doing age with technologies, which comprises the following elements (see Figure 1).

What differentiates these approaches from one another is, however, how all of these elements are conceptualized. First, they differ in their understanding of the individual; second, their understanding of the social; and third, their understanding of the material.

To put it simply: in rational choice theories, the individual is defined as a fully agentic human subject whose actions are rational and intentional. The social and the material are only relevant for those actions in as far as they are positive or negative outcomes or resources. In structural-institutional theories, the individual is subject to powerful structures and institutions. Materialities are manifestations of those power relations. Poststructural theories, finally, want to get rid of the micro-macro divide by placing emphasis on knowledge. Social phenomena on both levels are constructed in a process involving various actors, and some of them grant the human individual equal agency as the material.

From a rational choice perspective, technology is mainly perceived as a means to support active and successful aging. The chances of reaching these outcomes are, however, not equally distributed across the population, as a structural-institutional perspective might add. Post-structural theories, finally, go a lot further in claiming that age itself is constructed through, inter alia, the (use of) technology, and focus on how this is being done-through discursive formations, social practices and materialities. Practice theories incorporate the core elements of both rational and structural-institutional theories, but claim that they are qualities of a practice, not and individual or a society. The individual is, from this perspective, a "bodily and mental agent" (Reckwitz, 2002, 250) that can be understood as a carrier or host of practices. It is therefore neither a rational actor nor a structurally determined "dope," but a skilled agent.

In the following section, we want to carefully discuss how a praxeological terminology based on Bourdieu can be enriched with notions of STS to research the doings of age in a digitized world in what we call a "material praxeology of aging with technology."

\section{A MATERIAL PRAXEOLOGY OF AGING WITH TECHNOLOGY}

There are three core assumptions we can draw from the theoretical discussion: first, age is not a biological attribute, but rather a practical process that is being done. Age is constituted of and constructed through social practices, of doings and sayings. Second, both human and non-human agents are involved in 


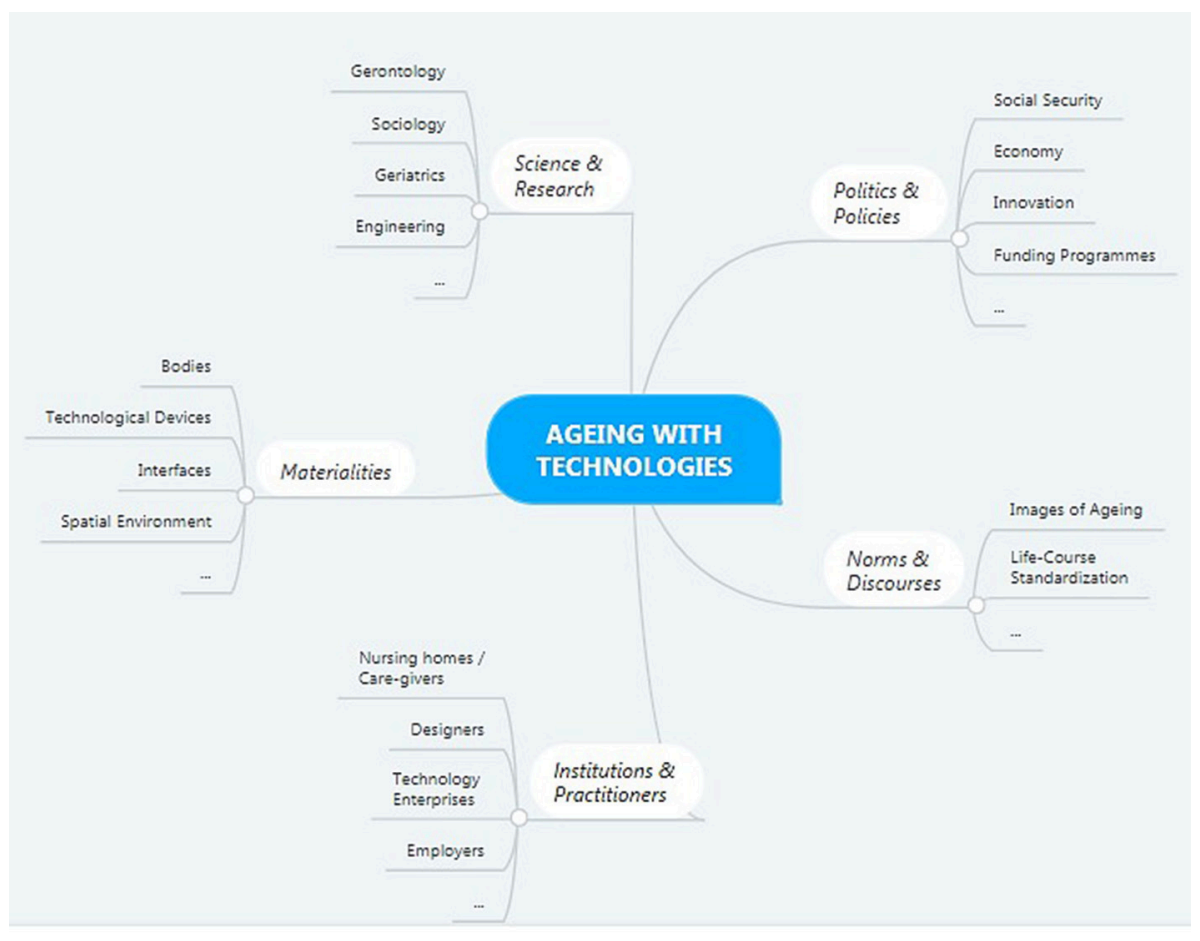

FIGURE 1 | Elements of the field of technologies and aging.

this process. Age is being done by policies, knowledge, bodies, scientists, technologies, designers, spaces, and much more. In Bourdieu's terms, we understand these agents and doings as embedded in power structures within a social field. Third, we take up the notion of distributed agency within a field, which we will conceptualize further through a Bourdieuan idea of structured-and therefore unequally distributed-agency.

In the following section, we want to lay out a material praxeology of aging with technology as a theoretical proposition that is based upon these assumptions. This calls for the consideration of (1) the doings of age, (2) human and non-human agents, and (3) varying degrees of power in the analysis of aging and technologies. We call this approach a material praxeology of aging with technology. By this, we aim to equally "praxeologize" and "materialize" the study of aging and technologies. This implies the introduction of Bourdieu's terms "field" and "habitus" to the study of aging and technologies, as well as the introduction of emphasis on non-humans to a Bourdieuan concept of agents and agency. Such an approach can guide us in approaching the main question of this paper: how is age being done in a digitized world? Which elements constitute the doings of age with technologies?

Taking our theoretical considerations into account, we want to further ask: what is the field of technology for older adults and how is it constituted? What are the field logics and the resulting ways of acting within it? Which agents are involved and how are they positioned? How does power come into play in the constructing of age with and through technologies?

\section{The Field of Technologies and Aging}

Looking at the field of technology, we can extract the doxa of the field or "rules of the game" as driven by innovation. Technology developers have to continuously develop new things, and users are nudged to continuously adopt new technologies, hence acquire new forms of knowledge and enroll in new practices. If researchers in the field of technologies submit a project proposal for funding, the innovation of the new product or research must be laid out; and if it lacks innovation, it will not be funded. Devices themselves, once developed, play their part in the innovation doxa through obsolescence - may it be planned by the developers and scripted (cf. Akrich, 1992), or due to a lack of updates or lack of compatibility with other devices. Depending on their position in the field, agents re-act to this doxa: if they are young and rich in cultural capital, they might frantically adopt new technologies before anyone else does (cf. Beal and Bohlen's "early adopters," 1957); if they are old and less educated, they might lag behind the technological innovation process ("laggards"; ibid.) or even resist it.

The development of technologies specifically developed for older adults might be seen as a hybrid between the field of technology and the field of old age. This enables us to reflect on how diverse social fields overlap in the constitution of the field doxa. Social fields are relatively autonomous, but interconnected in the way that agents and forms of capital move between them. Emerging fields in particular can be understood as arenas in which the field doxa and capital structure are yet contested (Swartz, 2013). A field emerging in between the fields of technologies and the field of aging then becomes 
an arena in which power relations between different agents (e.g., businesses, seniors' organizations and technicians) are continuously negotiated, social positions are distributed and fought out. The innovation logics of the technology field merge with the logics produced within the "aging enterprise," namely that of active aging vs. deficiency and dependency. This merging results in a doxa of creating innovation with "positive outcomes" for a user group otherwise framed as unable to live healthy and active lives. Technologies for the aged must not only be innovative; they should also increase life expectancy and improve health, mobility and autonomy. With these principles, agents act depending on their relative position in the field, i.e., depending on whether or not they are rich in economic capital, like funding bodies or wealthy consumers; whether or not they are rich in cultural capital, like technology companies; and whether or not they are rich in social capital, like marketing firms. Understanding aging and technologies as an arena therefore enables us not only to look at the dominant forms of capital that are relevant in the field, but also to reflect upon which agents are competing for a legitimate and powerful position with their capital.

\section{The Agents}

Understanding aging and technologies as a field then calls for a careful consideration of what constitutes an agent within a field. Traditionally, Bourdieu's praxeology conceptualizes humans as the main actors within a field, even though artifacts might hold an agential position as part of the habitat. In contrast, STSand most prominently Latour's ANT-have granted artifacts the status of fully agential actors within a network. Social phenomena, in this sense, are understood as a convergence of multiple interacting influences, which can include human and non-human elements (Elder-Vass, 2014). To conceptualize human and non-human actors within a field as part of our material praxeology, we therefore want to lay out some basic assumptions of STS approaches in their definition of an actor within a network.

From an STS perspective, actors are no fixed or defined entities, but gain their status as actors only within the network to which they belong. The social world is, then, not an assemblage of different actors, but an assemblage of relationships and interactions between them. In this continuous flow of interaction, it is a challenge to define which elements or characteristics constitute an actor. For Latour, actors are only vaguely defined as elements that modify the network. Actors are everyone and everything that modifies an action by making a difference (Latour, 2005). Actors within a network are therefore not defined by their characteristics but by their capability of modifying a network as "a series of transformations-translations, transductions" (Latour, 1999). It is therefore not the actors themselves, but the transformative affects they cause in a network that makes them relevant as actors.

Even though diverse approaches within STS differ in in their definition of what constitutes an actor, it is their understanding of the human and non-human as equally agentic that distinguishes them most clearly from Bourdieu's praxeology. Latour criticizes structural sociology (which he calls "classic socology") for knowing "more than the 'actors'; it sees right through them to the social structure or the destiny of which they are the patients" (Latour and Porter, 1996, 199). It is, however, exactly this emphasis on social structures that defines what Pierre Bourdieu conceptualizes as an agent. Even though both authors share their perception of the actor/agent as a relational category (Schinkel, 2007), Bourdieu sees agents in their relative position to other agents in a social field-including differences in the agents' levels of power. Agents in a field are therefore not equal-they possess varying amounts and structures of capital, have different chances to act and to have an effect within a social field (Bourdieu, 1989). For Bourdieu, agents have the ability to possess capital and take up a position within a social field. Therefore, technologies would not be agents, and in his work, Bourdieu doesn't treat them as such.

This does, however, not mean that material aspects are negligible parts of social practice. In "On Television" (1996), Bourdieu emphasizes how technologies are socially shaped through their meanings for the different social groups that use them (Bourdieu, 1996). Analyzing technologies-in a Bourdieuan sense-means understanding technologies as "crystallized parts of habitus, (...) a particular form of practical reason" (Sterne, 2003, 376), or-as Schmidt (2008) has suggested-understanding them as part of the habitat, an objectivized form of social practice. Technologies are, for Bourdieu, not agents on their own, but gain agentic relevance through their use by human agents. The habitus, in that sense, is not entirely bound to human agency, but only set into practice through interaction with an agents' habitat and the artifacts that constitute it. This conceptualization puts emphasis not so much on different human and non-human actors, but the relations between humans and the habitat through the habitus (Schmidt, 2008). The habitus is then a relational category, emergent from the field's agents, power structures and habitat.

Even though we agree with Bourdieu on the importance of power relations between agents, we want to emphasize that non-humans, as part of the habitat, can act as part of the habitus within a field. This presupposes that non-humans, like technologies, can have capital. Technologies might not own money, but they can "possess" economic capital in the sense that they (and their patents) are worth money. They might not have educational certificates, but they can be certified if they meet certain technological standards. Their cultural capital might otherwise not be embodied, but can be incorporated ${ }^{2}$, as they can also be more or less skilled in functioning with other technologies, artifacts, or humans. They can have social capital in communicating with other technologies and/or acting with other humans. They can call for a certain way of acting with them and, more importantly, they might require their users to possess specific forms of capital to be able to use them.

Hence, we propose viewing technologies and other nonhumans agents from a Bourdieuan perspective, which means

\footnotetext{
${ }^{2}$ Following Gilleard and Higgs' distinction between embodiment as expression of personal Gilleard and Higgs (2015) identity (2015) and corporeality, it might be misleading to talk about a technology's embodied capital; hence, the term "incorporated" will be used in this regard.
} 
understanding them as part of the habitat. This implies that they occupy different social positions and are, hence, powerful to different degrees. Consequently, it implies that their agency is just as structured and bound as that of Bourdieu's human agents.

\section{Social Practices and Power}

The relative social position a-human or non-human-agent occupies within a field delimits its ability to act. In such an understanding, "doing something" is always bound and dependent upon one's position within a field. The habitus, as a complex of social practices, is not individual, but collective; not rational, but structured; and not flexible, but inert-taking the concept of agency far away from individuality, rationality and intentionality that it is otherwise often associated with. An STS understanding of agency would dismiss individuality, rationality, and intentionality in a similar way. However, it would imply a much stronger emphasis on variability, fluidity, and precarity of social practices that, at first sight, seems to be diametrically opposed to Bourdieu's emphasis on reproduction. For Latour, for example, agency is not just an outflow of pre-existing structures; it is something that is being produced over and over again within actor-networks. Agency is not bound to certain actors, but is distributed within the network-as Kipnis (2015) puts it: "No agency exists as an isolate" (p. 50). This distribution comprises both human and non-human parts of the network. In this, STS agency is much more "random" or "surprising" than Bourdieu's habitus, which is prone to reproduce social practices.

More recent practice theories draw upon both Bourdieu and STS to conceptualize social practices (as opposed to habitus and agency). They are the "sites" from which action emerges, and hence incorporate both the actors and the networks. But neither people nor technologies participate in practices by chance. Both are bound by their socialization (humans) resp. scripts (technologies), and their relative position within a field. Just as people tend to follow a routine, and hence reproduce practice, a washing machine tends to act according to its script and wash. Yet, neither human nor non-human agents are completely determined by this. Social practices exist as both entitiessimilar to scripts or, from an expanded view, the field doxa-and performances, carried out in situ (Shove et al., 2012). They thus emerge from a situation, but also always follow predefined rules, norms and scripts of how they are conducted properly (Reckwitz, 2002). These norms are implicit, incorporated, and consist of a variety of micro-practices.

As the competence to become part of practices varies between them, and hence the duration of training (or socialization) varies, some practices are less prone to change than others. Additionally, power mechanisms contribute to maintaining the reproduction of some practices and the change of others. Performing or "doing gender" (Butler, 1991), for example, is trained and inscribed from birth onwards, and power relations tend to maintain it, while other practices-like acting with technologies-are easier to learn and "un-learn," and power relations tend to change them more rapidly.

Summarizing, a "material praxeology" that considers both the field logics and power relations conceptualized by Bourdieu and, at the same time, grants more relevance to materiality, needs to make the following assumptions:

1. Social fields, as relations of power structures, constitute the contexts in which age as a social phenomenon is being done with and through technologies. These power relations can play out differently in different situations, depending on the forms of capital relevant in these situations.

2. Human and non-human agents-individuals, institutions, bodies, discourses, and technological devices-are equally involved in this process. Technologies, in particular, can be both targets and initiators of action, as well as partners in interactions with humans.

3. The social practices that emerge within these fields are structured through power relations. These practices may change or reproduce themselves, depending on the level of competence and capital necessary to participate in them and the power relations that either hold them in place or make them change.

\section{EXERCISE GAMES FOR OLDER ADULTS-AN EMPIRICAL EXAMPLE}

A theory can only be evaluated by its resonance to empirical appliance. We want to do this here with the example of a socalled "exergame," which is being developed in the course of a scientific project. Exergames are a hybrid between videogames and exercise programs that aim at providing an unobtrusive and "fun" way to physically exercise (Kharrazi et al., 2012). As they are being played via bodily movement, they require certain sensors to track the user's movements. Exergames are being developed for different target groups, may it be completely healthy children and (young) adults (like Nintendo's Wii), or convalescents, persons with chronic illnesses, disabilities or dementia.

To exemplify our approach, we will use one specific project as an illustration. The project with the abbreviated title "ExerFun" has been funded by the AAL Joint Program (AAL-JP) of the European Commission. It was a three-year international and inter-disciplinary project in which engineers and technicians, designers, advertisers, care service providers, and sociologists at universities, private corporations and NGOs worked together. As required by the AAL-JP, the project involved methods of enduser involvement. Older adults were asked about their needs and wishes before the system development started and they were involved as test users in field pilots during which the system was developed further.

\section{The Field of Active and Assisted Living Technologies and its Antagonisms}

The ExerFun project can be located within the field of "Active and Assisted Living (AAL)" technologies. The concept of AAL developed out of the term "Ambient Assisted Living," which was abandoned in 2013 for its focus on care technologies, and received a new coat of whitewash to also attract healthy and active

${ }^{3}$ The name of the project has been anonymized. 
third agers. The field was predominantly shaped by the AAL-JP, a huge European funding body which was also leading in the formation of the "rules of the game" (doxa). On its website ${ }^{4}$, three major aims are listed that capture the doxa of the field:

\begin{abstract}
"Foster the emergence of innovative ICT-based products, services and systems for aging well at home, in the community, and at work, thus increasing the quality of life, autonomy, participation in social life, skills, and employability of elderly people, and reducing the costs of health and social care.

Create a critical mass of research, development and innovation at EU level in technologies and services for aging well in the information society, including the establishment of a favorable environment for participation by small and medium-sized enterprises.

Improve conditions for industrial exploitation by providing a coherent European framework for developing common approaches and facilitating the localization and adaptation of common solutions which are compatible with varying social preferences and regulatory aspects at national or regional level across Europe."
\end{abstract}

This exemplifies how the doxai of different fields merge within the field of AAL-norms, beliefs and ways of knowledge around technologies, aging, science and the economy mingle, complement, and contradict each other. Technologies to be developed in this field must be (framed as) innovative and bring economic profit; but they must also have a positive outcome for their users und contribute to positive aging. Positive aging is defined here by autonomy, social participation, employability and health. This operationalization depicts the demands that older people are facing today-or the doxa of aging-to be independent, socially engaged, productive, and healthy.

However, societal images of aging are not only shaped by a shift from disengagement to activity, but also by the increasing heterogeneity and individualization of older adults. An innovative technology that meets the demands of a diverse consumer group must, consequently, adapt to the individual needs and preferences of each single user. The ExerFun project aimed to follow these logics by...

"[..] combining three core aspects of $A A L$ [...]: new, innovative technology for sensing relevant mobility and gaming characteristics of individuals is used to drive a personalized gaming platform that serves the needs of the end-users in their private homes and increases their quality of life" (ExerFun Project Proposal, p. 4)

The technology set out to adapt itself to the personal preferences and skills of its users, emphasizing the heterogeneity of older adults, but not without pointing to the "risk of losing an active lifestyle and the connection with the society" that accompanied the status of "older adults living alone in their private homes," which were defined as its target group (ibid: 4). This was to be achieved by combining "different technological innovations" that would result in a smart technology that could, on the one hand, automatically adapt to its users and would hence be "unobtrusive" (a word used nine times in the proposal) and

$\overline{{ }^{4} \mathrm{http}: / / w w w . a a l-e u r o p e . e u / a b o u t} /$ objectives/ [Accessed 08.11.2017; 15:30]. "interoperable" (a word used 20 times in the proposal). Thus, the innovation logics of the technology field merge with the logics of aging between activity and deficiency.

Moreover, logics of scientific research merge with logics of economic profit: predefined success parameters comprise "statistically and scientifically valid results" and "randomized controlled trials," and the value of a "scientifically and statistically sound evaluation" is stressed in several pages of the project proposal. However, $56 \%$ of the total project costs is dedicated to business partners, while only $32 \%$ is dedicated to research organizations. This elucidates the different social positions and degrees of power among the agents involved.

\section{Agents and Power Relations}

Who and what are the agents in this example? In her situational analysis, Clarke (2005) proposes a framework that can be used to structure the different actors involved in a situation. She suggests listing human and non-human, collective and implicated actors, and their discursive constructions, as well as political, sociocultural, temporal, and spatial elements as actors. We want to apply this way of structuring to our empirical example (however, substituting the term "actor" with the term "agent") and consequently discuss power relations between these groups of agents.

\section{Human and Non-human Agents}

First and most obvious, the project gathered several collective agents, namely eight partner organizations from five countries: one software and consulting company, two university departments (one technical, one sociological), two NGOs (one working with disabled older adults, one working with healthy older adults), two technology development enterprises and one geriatric hospital. The funding initiative, AAL-JP, was involved both centrally as a European body and locally in each state of the project partners.

In each organization, teams of several individual human agents were assigned to the project. Moreover, the so-called "primary end-users"-older adults aged 65 years and older-were involved in the requirement analysis survey and the field pilots to test the developed system. In addition, "secondary end-users," i.e., care personnel, were involved in focus groups and field pilots.

The central non-human agent was the technology being developed. The technical system consisted of a console, a television screen, and a sensor to capture bodily movements. These things require a certain spatial arrangement in the apartments at which they were to be installed. As the console and the sensor were to be connected to an already existing television flat-screen, there needed to be a space of about $4 \mathrm{~m}^{2}$ in front of the screen to ensure safe "exer-gaming."

Bodies occupy an interesting position between human and non-human agents, as they are predominantly material, yet hardly non-human. In the project, the bodies of older adults were of major concern: they were to be moved in accordance to the games, and this bodily movement posed major challenges to the development process. A sensor had to be developed to capture bodily movements most accurately, the software had to be designed so as to translate those captured movements into the 
movements of the game avatars with almost no delay and the difficulty, as well as the speed, of the expected movements had to be adjustable to cater to a wide range of physical conditions.

\section{Implicated and Discursive Agents}

The above mentioned agents were involved in many project situations, even when they did not physically attend. Clarke (2005) talks of "implicated actors" when absent actors are referred to in a situation. They are most obvious in the scripting of technologies with a specific end-user in mind (cf. Akrich, 1992), and this process is systematized within AAL projects: a target group has to be described in the funding proposal and the characteristics of this target group are continuously and systematically synchronized through stages of end-user involvement. To receive funding from the AAL-JP, implementing such an end-user involvement process is mandatory. Hence, the imagined older end-user was, whether physically absent or present, a constant companion to the project. They were addressed and referred to, and hence acted, via what can be framed as traces of their needs and opinions - graphs presented their answers to questionnaires, interview transcripts, references to literature about them or through the voices of the enduser organizations that are part of the project to vocalize their demands in a structured and qualified way than is believed they could do themselves.

Not only the imagined end-users, but also the imagined technology was continuously referred to-even though not yet existent-in the course of the project: in the proposal, during project meetings, in marketing strategies, and in conversations with the end-users. Its qualities, demands, and ways of functioning were imagined in alignment with the (supposed) end-user qualities and demands. For this purpose, prototypes were designed, which should represent the not-yet-existent technology in the discussions.

Beyond the imagined end-users and technology, collective agents became implicated agents. The funding sponsors, for example, would primarily act via the research proposal, which served as the planned imagination of the approved project. Every deviation from this plan was negotiated with the funding sponsors in mind: would they approve of a prolongation of the second work-package? Similarly, "the market" was a collective implicated agent, as the project should make the developed technology ready for the market. Would the market appreciate the system? In regards to technologies for older adults, the market is not to be equalized with the end-users. This is first and foremost due to the fact that many technologies are so expensive that only a small share of individuals could afford them. Hence, other collective agents, like health insurances or care facilities, might take on the role of the potential buyer.

Besides implicated agents, which refer to specific human or non-human agents referred to in the research process, discursive agents comprise wider societal imaginaries, and fields of knowledge. Conceptually, we want to differentiate between doxa as the overarching logic of the field (see The Field of Active and Assisted Living Technologies and its Antagonisms) and guiding principles and ideas that played a less overarching, yet distinct role. One of the discourses that became an agent in the course of the research project was the ethics discourse. Its emergence is partly inherent in the field doxa, as the innovation logics imply development of technologies that are new and unfamiliar to the end-users and relevant stakeholders, and hence their functioning will be partly non-transparent. Ethical issues in AAL may comprise questions of privacy, control of personal data, confidentiality or autonomy ${ }^{5}$ Therefore, certain provisions have to be taken against academic misconduct, like the use of an informed consent to ensure the voluntary and undeceived participation of end-users. The ethics discourse has, however, become so professionalized that measures cannot be left in the hands of the project consortium, funding bodies or legal requirements alone. Instead, the vote of an external ethics committee is increasingly needed to publish results gathered in AAL projects. Hence, through the facilitation of ethics as a discursive agent, the collective agent of the ethics committee entered the project (see Figure 2).

\section{Social Positions and Power}

Applying this list of agents to our outlined theoretical approach calls for a comparison of the agents' different social positions and degrees of power. According to Bourdieu, social positions result from the amount and form of available economic, cultural and social capital (Bourdieu, 1984).

The most powerful agent in terms of economic capital was the AAL-JP and its national administrations. As the primary funding bodies, they could decide over the disbursement of budget rates or deem expenses as ineligible. In terms of budget allocation, the business partner organizations received the highest share with $56 \%$, followed by research organizations with $32 \%$ and end-user organizations with $12 \%$. But even though this points to unequal power relations between collective agents, the technology to be developed played a major part in this distribution: the acquisition of hardware, for which the business partners were mainly responsible, was expensive; and the economic profit it might bring in was promising, resulting in the tedious creation of an Intellectual Property Rights (IPR) agreement.

End-users involved were predominantly middle-class individuals, but as an imaginary, they were the customers from which to generate profit. Much more than their economic capital, their position was defined by their social capital: they constituted the wealth of social capital for the end-user organizations, which would not have been involved in the project otherwise. Curiously, however, it was a different form of social capital that was granted most relevance throughout the research processthe social capital of the technology or, put in other words, its interoperability. The possibility of communication between the developed software and other existing AAL systems and services was one of the primary project objectives.

Cultural capital played out in its institutionalized, embodied and objectivized form. Institutionalized, it structured the relations between the individual members within and between the partner organizations. Those with higher qualifications

\footnotetext{
${ }^{5}$ Guide for Applicants Ambient Assisted Living Joint Programme Call 6: http://www.aal-europe.eu/wp-content/uploads/2013/02/ Guide_for_Applicants_20130211final.pdf
} 


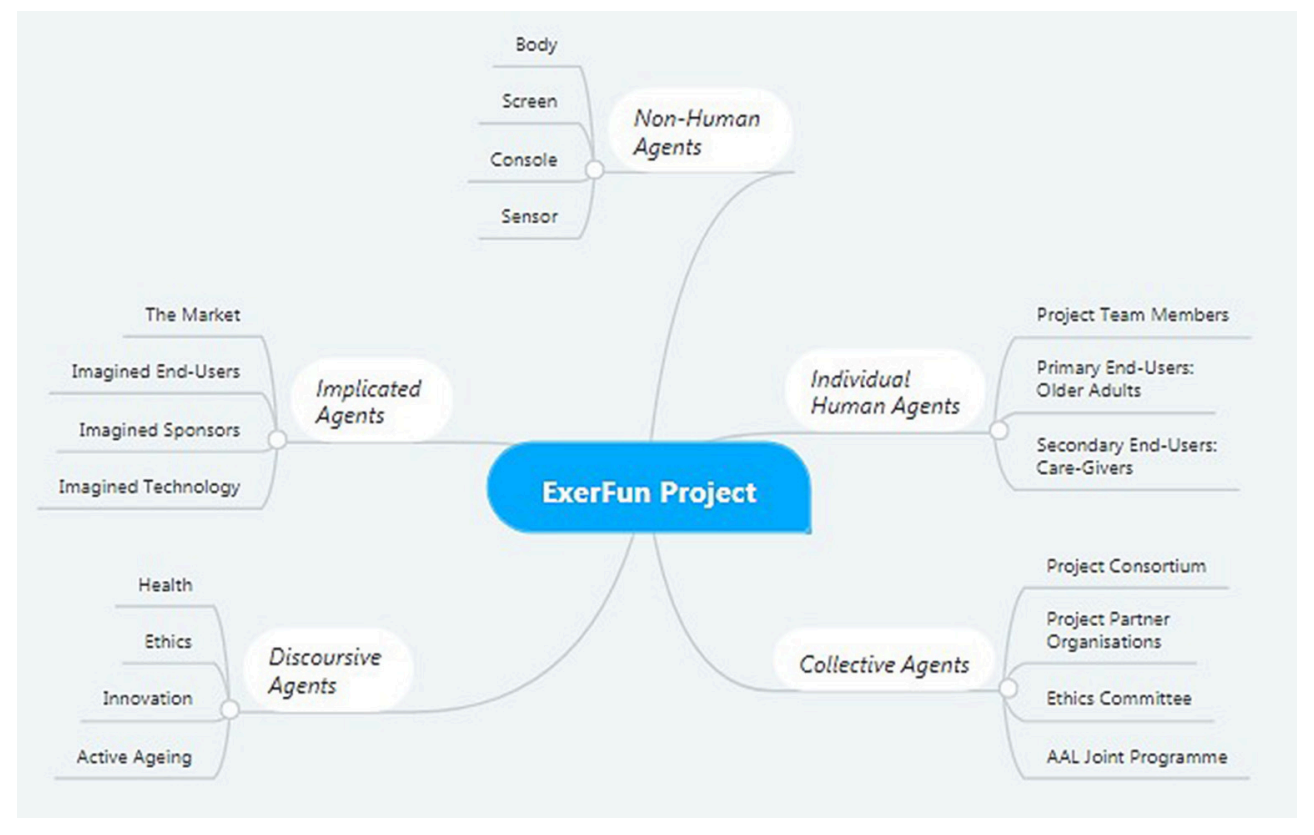

FIGURE 2 | Agents in the ExerFun Project.

were usually higher in the professional hierarchy and occupied positions of project leaders or senior researchers, as opposed to assistants and junior researchers. This also applied to collective agents - most university personnel held university degrees, whereas personnel of the end-user organizations had no academic background. Hence, they lacked legitimized knowledge about the proper reading of data or good scientific conduct, creating inequalities between the collective agents.

The most valuable form of cultural capital, however, was the understanding and competent use of the developed technology. The ability to competently play exergames was central within the project, and it was unequally distributed across individual and collective agents-for example, engineers were more competent than sociologists. Framed as most incompetent, however, were the older end-users. Young, male engineers with high technological competence as the developers of the technology were in stark contrast to the older, and often female, adults with little to no technological competence as imagined users.

To be playable by those supposedly unskilled individuals the technology should be able to "learn" about its users and adjust to their needs and preferences. The incorporated cultural capital of the technology was, thus, to competently "play" the users just as they should competently "play" the exergame. The older users, hence, were as much the target of the technology's incorporated cultural capital as the technology was the target of their embodied cultural capital.

\section{Social Practices and Power Dynamics}

Amidst the specific field logics and the social positions of the involved agents emerge social practices, and these practices constitute social phenomena. In this section, we particularly want to focus on the processes in which the developed technology acted to co-constitute age within the project. In an exemplary manner, we will describe three constellations of practices

1. that target technologies

2. in which technologies initiate dynamics and

3 . in which technologies interact with bodies.

In all these processes, power relations pre-structure human and non-human action and we will shed light on how they did so in the project.

\section{Practices That Target Technologies}

With the first example, we want to show how constellations of social practices target technologies, namely by practices of scripting as shaping the future trajectory of technological action. In the ExerFun project, a predecessor technology already existed, which should be enhanced in the course of the project. Its intended use scenario or script (Akrich, 1992) was a hospital, rehabilitation center or nursing home, in which older adults would play the game with the assistance of a professional (e.g., physiotherapist). The newly developed technology, however, should be used at home by older adults of different fitness levels and without professional assistance. With this, the project reacted to the call's main objective, namely to support aging in place.

The example scenario laid out in the project proposal described a 66-year-old man and his 85-year-old mother. The son was active and healthy, but he perceived available exergames as too fast and stressful; his mother was facing mobility restrictions and "is not really into modern technology" (ExerFun Project Proposal, p. 7). This user imagination sets the limits within which older adults may be heterogeneous: while all older adults lose physical abilities, become slower and are thus not quite able to use "normal" technologies, there are differences in the severity 
of this decline - male third-agers are still better off than female fourth-agers. To cater to this, yet limited, diversity, the system was designed to adapt different abilities and preferences to its users.

It would, however, be misleading to state that the project stopped at this stereotypical use scenario. It much rather integrated end-user involvement at various stages (e.g., a requirement analysis in the beginning, focus groups, and different stages of field pilots to test the technology).

The practices of end-user involvement can help us exemplify how power relations play into the scripting of technology. The crucial struggle for power is targeted around the question of who may represent the older adult. Already within the consortium, the partner organizations started to compete for the role of being the most authentic voice of the older endusers. They struggled for the power to define which end-user image would, in the end, be inscribed into the technology. To gain power, they played out their cultural capital: the sociologists argued with data and scientific methods as the only scientifically sound means to thoroughly scrape out end-user needs and wishes; the end-user organizations contended that only they knew about the difficulties older adults were facing in their everyday lives-a kind of knowledge that was more practical and not as out-of-touch with the real world as the sociologists' knowledge; and the geriatricians recognized that sociologists and representatives might know about older people's attitudes and behavior, but that this knowledge was worthless without knowing about their physical capabilities. Finally, the battle for creating the most credible end-user imaginary was not won with cultural, but rather social capital. As the enduser organizations were responsible for the recruitment of participants, they were gate-keepers to which end-users might be involved. This finally shaped the new imaginary of potential end-users and scenarios to be inscribed into the technology. Fourth-agers who had difficulties going outside and who received home-care by the end-user organization should play the game at home, but under the supervision of their care-givers. The first emergence of action thus described how technologies were used as the target of action, and how different agents played together in inscribing end-user imaginaries and use scenarios into them.

\section{Practices in Which Technologies Initiate Action}

Whereas it is rather uncontested that technologies can be the target of action, the question of if, and how, they can initiate action is more difficult.

As mentioned above, the developed exergame was supposed to learn about its users. Practices of machine learning are, just like human learning, dependent upon experience, and things are experienced through the senses. Whereas humans experience environments with their eyes, ears and skin, non-humans may learn via sensors. These sensors are able to analyze motion based upon an algorithm and gather depth images that are being processes locally. Even though as much privacy as possible should be ensured with this, it evoked questions about data security. Beyond this, the learning aspect evoked concerns about the physical safety of its users' bodies: what if the system failed to correctly assess its users' level of fitness and adapt the game difficulty accordingly and the user would fall or get hurt? And if neither data security nor physical safety could be ensured during the trial period-as a trial is, precisely, intended to detect such pitfalls in the first place-how could people be motivated to participate in the field tests? Would they have to be informed about all possible risks - wouldn't that be deterrent? And if they were informed, could they understand a complex sensor system?

All of these questions touch upon ethical issues. The functioning of the technology, hence, induced the entering of an ethics discourse, and finally the collective agent of an ethics committee, into the project. As many scientific journals require the vote of an ethics committee, the internal handling of ethical issues turned out to be insufficient. Hence, an ethics proposal was submitted to an external ethics committee. This proposal was drafted by the project partners carefully with the technology in mind-just like the technology itself was being scripted with its possible users in mind. In this situation, hence, technology as the non-human agent exerted power over the individual agents; yet it was not as powerful as the ethics committee, whose vote could seal the continuation, extensive delay or even termination of the project.

\section{Practices in Which Technologies Interact With Bodies}

The previous situations have exemplified how technology can be the target of action. Most often, however, technology interacts in a close-knit nexus of action and re-action. This can be exemplified when we observe the core practices of interaction between bodies and the technology-playing games via bodily movements.

Exergames work by interconnecting human and nonhuman actions via the translation of movement. Therefore, the technology consisted of three elements: a console for the software, a television screen for visualization, and a sensor that transferred motions of human bodies to the console, where the software translated them into motions of digital avatars that were to be visualized on the screen.

The software contained a range of different mini-games. One of them was called "Volleyball." It portrayed a comic-style version of a beach and a volleyball net, as well as two avatars. It could be played by either two persons or the second avatar could be operated by the system. With the start of the game, a volleyball appeared, falling toward one of the avatars. If the human player resembling the respective avatar raised their arms, the avatar did the same; and if they were raised in time, the ball was caught and thrown back over the net by the avatar. If the body movement was too slow or not vigorous enough, the ball fell to the ground.

When we reflect on this gameplay, we can see how a variety of agents has to act together in very short intervals to facilitate a flawless process within the nexus of social practices. When the game starts, the software acts to display a stimulus on the television screen - the volleyball appears. The individual human player(s) enter(s) the game when they start to move-no matter if their movement is accurate, i.e., fast and vigorous enough, or not. When the sensor captures movement and recognizes it, it 
assesses its speed and strength and transfers the signal to the software, where it is translated into avatar movement that is to be, again, depicted on the screen. This nexus of action and reaction happens in the course of a few seconds, and it is dependent upon the collaboration of every agent involved.

How does power come into play here? By defining power as the capacity to direct or influence the actions of others, we can see that all agents are powerful in some way. Exergames pose an interesting case here. Contrary to, for example, exercise videos, the users are not supposed to repeat the actions they see on the screen; rather, the game is supposed to repeat their actions and translate them into visible movement on the screen. The avatars, hence, follow the movement of the human players - even more so, as the software is supposed to learn about the capacities and preferences of its players. However, once having entered the game, the scope of action for the human players becomes limited. In the volleyball game they can do little more than move their arms; if they do anything else their actions will be ignored by the sensor. Hence, the system needs its humans to participate to facilitate a proper game; but if they do, they must play by the system's rules.

\section{IMPLICATIONS, LIMITATIONS, AND OUTLOOK}

In this paper, we have laid out a post-structural account of understanding aging in a digitized world. In what we framed as a material praxeology of aging with technology, we are concerned with how age is being done through discursive formations, social practices and materialities and how social inequalities are reproduced through these elements.

In the beginning of this paper, we presented an overview of approaches that have been used to study aging and technologies so far. From this overview, we extracted three core assumptions for our theoretical development: First, age is not a biological attribute, but rather a practical process that is being done. Second, both human and nonhuman agents are involved in this process. And third, these agents possess different social positions and degrees of power. Their contribution to the joint doing of age, hence, differs.

Based on these cornerstones, we set out to develop a material praxeology of aging with technologies. Such a "material praxeology" that considers both the field logics and power relations conceptualized by Bourdieu and, at the same time, grants more relevance to materiality, needs to make the following assumptions:

1. Social fields, as relations of power structures, constitute the contexts in which age as a social phenomenon is being done with and through technologies. These power relations can play out differently in different situations, depending on the forms of capital relevant in these situations.

2. Human and non-human agents-individuals, institutions, bodies, discourses and technological devices-are equally involved in this process. Technologies, in particular, can be both targets and initiators of action, as well as partners in interactions with humans.

3. The social practices that emerge within these fields are structured through power relations. These practices may change or reproduce themselves, depending on the level of competence and capital necessary to participate in them and the power relations that either hold them in place or make them change.

With the example of the "ExerFun" project, we depicted how such an account can help us to understand how age is constructed in the process of scientific projects in the field of AAL. Such a project is a rich depository of data, situations and materializations in which age is being done.

What are the implications and points of criticism for following a material praxeology of aging with technologies? We argued that formulating a Bourdieuan praxeology that takes materiality seriously improves our analysis of the coconstitution of age and technologies. Within this approach, aging and technologies are co-constituted in a social field, comprised of actors, discourses and power relations. In our empirical example, we tried to show how the actions, which emerge from such a field, are always structured by the power relations between the agents involved, but that these power relations can work out differently in different situations. Also, the agents most resourceful in terms of capital must not always be the most influential. The end-user organizations, for example, were conclusive in the definition of an enduser imaginary, even though they largely lacked economic and cultural capital.

Defining technologies and aging as social fields will enable future empirical analysis to focus more closely on the power relations that accompany the development of technology, as well as the doings of age. However, the field notion comes with a strong emphasis on the field doxa, which sets the standards for all actions within the field. Hence, it can be criticized that the field notion implies a deterministic relation between the field and its agents. This holds partly true for the example given; however, it must not hold true for other examples. First, the field doxa is historically contingent and thus prone to change. As the AAL field merges doxai of other fields, a change in them is likely to affect the AAL doxaif, for example, a different understanding of age emerges in the gerontological field, or logics change in the technological field, the AAL doxa will most likely change in correspondence. Hence, aging researchers can influence the way in which action is structured within the AAL field. This applies particularly when changes in related fields are accompanied by changes of power relations in the respective field. If, for example, the sociologists would have supported a different image of aging, and had had more power, the doxa of the field of sociology might have taken over the doxa of the AAL field and might have been more influential in structuring action. Another example is the obligation to include end-user involvement processes in AAL projects. Even though such processes can be heavily criticized, this requirement grants the end-users, and their representatives, a certain amount of power and 
structures action differently than it would have been if only engineers and designers were involved in the technologydevelopment.

Concluding, we want to argue that taking power into consideration does not presuppose a causal determinism, nor does it restrict action altogether; power much rather increases dynamics between the involved agents, and structures the pathways of action instead of just delimiting it. Considering power from a processual, post-structural and social-constructivist perspective points our attention toward how social phenomena, like age, are constructed in the dynamic interplay between differently powerful agents, and how such processes and relations are prone to change, too. Moreover, we want to emphasize that such power struggles are not limited to (individual or collective) human agents, but are, in fact, becoming more and more technical. With machine learning, practices of scripting, for example,

\section{REFERENCES}

Ajzen, I., and Fishbein, M. (1980). Understanding Attitudes and Predicting Social Behaviour. Englewood Cliffs, NJ: Prentice-Hall.

Akrich, M. (1992). "The de-scription of technical objects," in Shaping Technology, Building Society: Studies in Sociotechnical Change, eds W. E. Bijker and J. Law (Cambridge, MA: MIT Press), 205-224.

Alaimo, S., and Hekman, S. (eds.) (2008). Material Feminisms. Bloomington, IN: Indiana University Press.

Amann, A., and Kolland, F. (2014). Das Erzwungene Paradies des Alters?: Weitere Fragen an Eine Kritische Gerontologie. Wiesbaden: Springer-Verlag.

Beal, G., and Bohlen, J. (1957). The Diffusion Process. Ames, IA: Iowa State University of Science and Technology, Cooperative Extension Service. Available online at: https://core.ac.uk/download/pdf/7044374.pdf

Blau, P. M. (1977). Inequality and Heterogeneity: A Primitive Theory of Social Structure, Vol. 7. New York, NY: Free Press.

Bourdieu, P. (1975). The specificity of the scientific field and the social conditions of the progress of reason. Information 14, 19-47. doi: $10.1177 / 053901847501400602$

Bourdieu, P. (1977). Outline of a Theory of Practice. Cambridge, UK; New York, NY: Cambridge University Press.

Bourdieu, P. (1984). Distinction: A Social Critique of the Judgement of Taste. Cambridge, MA: Harvard University Press.

Bourdieu, P. (1989). Social space and symbolic power. Sociol. Theory 7, 14-25. doi: $10.2307 / 202060$

Bourdieu, P. (1990). The Logic of Practice. Cambridge, UK: Polity Press.

Bourdieu, P. (1996). Sur la Télévision: Suivi de L'emprise du Journaliste. Paris: Liber.

Bourdieu, P., and Passeron, J.-C. (1990). Reproduction in Education, Society and Culture, Vol. 4. London; Thousand Oaks, CA; New Delhi: Sage.

Butler, J. (1991). Das Unbehagen der Geschlechter. Gender Studies. Frankfurt: Suhrkamp Verlag.

Choi, M., Kong, S., and Jung, D. (2012). Computer and internet interventions for loneliness and depression in older adults: a metaanalysis. Healthc. Inform. Res. 18, 191-198. doi: 10.4258/hir.2012. 18.3.191

Clarke, A. (2005). Situational Analysis: Grounded Theory After the Postmodern Turn. London: Sage.

Damant, J., Knapp, M., Freddolino, P., and Lombard, D. (2016). Effects of digital engagement on the quality of life of older people. Health Soc. Care Commun. 25, 1679-1703 doi: $10.1111 /$ hsc. 12335

Dannefer, D. (2003). Cumulative advantage/disadvantage and the life course: cross-fertilizing age and social science theory. J. Gerontol. Psychol. Sci. Soc. Sci. 58, S327-S337. doi: 10.1093/geronb/58.6.S327 are becoming increasingly independent of human agents involved.

Finally, we acknowledge that the empirical account given is less systematic and detailed than it should be, and want to encourage other researchers to apply a material praxeology to their data in a more thorough and thoughtful way, formulating questions and criticism to such a framework and, thus, developing it further.

\section{AUTHOR CONTRIBUTIONS}

The ideas and hypothesis tested in this paper arise out of AW's and VG's joint work in AAL projects at the Department of Sociology, University of Vienna. AW: wrote the first draft of the manuscript; VG: wrote sections of the manuscript. All authors contributed to manuscript revision, read and approved the submitted version.

Davis, F. D. (1989). Perceived usefulness, perceived ease of use, and user acceptance of information technology. MIS Quart. 13, 319-340. doi: $10.2307 / 249008$

Davis, F. D., and Venkatesh, V. (1996). A critical assessment of potential measurement biases in the technology acceptance model: three experiments. Int. J. Hum. Comput. Stud. 45, 19-45. doi: 10.1006/ijhc.1996.0040

Depner, A. (2015). Dinge in Bewegung-zum Rollenwandel Materieller Objekte: Eine Ethnographische Studie Über den Umzug Ins Altenheim. Bielefeld: Transcript Verlag.

Elder-Vass, D. (2014). Disassembling actor-network Theory. Philos. Soc. Sci. 45, 100-121. doi: 10.1177/0048393114525858

Endter, C. (2016). Skripting Age-The Negotiation of Age and Aging in Ambient Assisted Living. Ageing and Technology: Perspectives from the Social Sciences. Bielefeld: Transcript.

Estes, C. L. (1979). The Aging Enterprise. San Francisco, CA: Jossey-Bass Incorporated Pub.

Estes, C. L. (1991). "The Reagan legacy: privatization, the welfare state, and aging in the 1990s," in States, Labor Markets, and the Future of Old Age Policy, eds J. Myles and J. Quadagno (Philadelphia, PA: Temple University Press), 59-83.

Estes, C. L. (2014). The future of aging services in a neoliberal political economy. Generations 38, 94-100.

Folkers, A. (2013). Was ist Neu am Neuen Materialismus? Von der Praxis Zum Ereignis. Critical Matter. Diskussionen Eines Neuen Materialismus. Münster: edition assemblage.

Forsman, A. K., and Nordmyr, J. (2015). Psychosocial links between internet use and mental health in later life: a systematic review of quantitative and qualitative evidence. J. Appl. Gerontol. 36, 1471-1518. doi: $10.1177 / 0733464815595509$

Forsythe, D. (2001). Studying Those who Study us: An Anthropologist in The World of Artificial Intelligence. Stanford, CA: Stanford University Press.

Gilleard, C., and Higgs, P. (2015). Aging, embodiment, and the somatic turn. Age Cult. Human. 2, 17-33.

Haraway, D. (2013). Simians, Cyborgs, and Women: The Reinvention of Nature, London: Free Assoc. Books.

Helmreich, S. (2000). Silicon Second Nature: Culturing Artificial Life in A Digital World, Updated With a New Preface. Berkeley, CA: University of California Press.

Henderson, K. (1998). On Line and On Paper: Visual Representations, Visual Culture, and Computer Graphics in Design Engineering, Cambridge, MA: MIT Press.

Hirschauer, S. (2004): "Praktiken und ihre Körper. Über materielle Partizipanten des Tuns," in Doing Culture: neue Positionen zum Verhältnis von Kultur und sozialer Praxis, eds K. H. Hörning and J. Reuter (Bielefeld: Transcript Verlag), 73-92. 
Joyce, K., and Loe, M. (2010). A sociological approach to ageing, technology and health. Sociol. Health Illn. 32, 171-180. doi: 10.1111/j.1467-9566.2009.01219.x

Katz, S. (1996). Disciplining Old Age: The Formation of Gerontological Knowledge. Charlottesville, VA; London: University of Virginia Press.

Katz, S., and Marshall, B. L. (2004). Is the functional 'normal'? Aging, sexuality and the bio-marking of successful living. Hist. Hum. Sci. 17, 53-75. doi: $10.1177 / 0952695104043584$

Katz, S., and Peters, K. R. (2008). Enhancing the mind? Memory medicine, dementia, and the aging brain. J. Aging Stud. 22, 348-355. doi: 10.1016/j.jaging.2008.05.007

Kharrazi, H., Lu, A. S., Gharghabi, F., and Coleman, W. (2012). A scoping review of health game research: past, present, and future. Games Health J. 1, 153-164. doi: $10.1089 / \mathrm{g} 4 \mathrm{~h} .2012 .0011$

Kipnis, A. (2015). Agency between humanism and posthumanism: latour and his opponents. J. Ethnogr. Theor. 5, 43-58. doi: 10.14318/hau5.2.004

Knorr-Cetina, K. D. (1981). The Manufacture of Knowledge an Essay on the Constructivist and Contextual Nature of Science. Oxford: Pergamon Press.

Kollewe, C., Heitmann-Möller, A., Depner, A., Böhringer, D., Atzl, I., and Artner, L. (2017). Pflegedinge-Materialitäten in Pflege und Care. (mit Fotografien von Thomas Bruns). Bielefeld: Transcript Verlag, 15.

Krais, B. (1985). Der Begiff des Habitus bei Bourdieu und seins Bedeutung für die Bildungstheorie. Theorien der Erwachsenenbildung. München; Weinheim: Beltz.

Kunemund, H., and Tanschus, N. M. (2014). The technology acceptance puzzle. Results of a representative survey in Lower Saxony. Zeitschrift Gerontol. Geriatr. 47, 641-647. doi: 10.1007/s00391-014-0830-7

Latour, B. (1999). On recalling ANT. Sociol. Rev. 47, 15-25. doi: 10.1111/j.1467-954X.1999.tb03480.x

Latour, B. (2005). Reassembling the Social: An Introduction to Actor-NetworkTheory. Oxford: Oxford University Press.

Latour, B., and Porter, C. (1996). Aramis, or, The love of Technology, Vol. 1996. Cambridge, MA: Harvard University Press.

Marshall, B. L., and Katz, S. (2012). The embodied life course: post-ageism or the renaturalization of gender? Societies 2, 222-234. doi: 10.3390/soc2040222

Marshall, B. L., and Katz, S. (2016). How old am I? Digital culture and quantified ageing. Dig. Cult. Soc. 2, 145-159. doi: 10.14361/dcs-2016-0110

Neven, L., and Peine, A. (2017). From triple win to triple sin: how a problematic future discourse is shaping the way people age with technology. Societies 7:26. doi: $10.3390 /$ soc7030026

Niehaves, B., and Plattfaut, R. (2013). Internet adoption by the elderly: employing IS technology acceptance theories for understanding the age-related digital divide. Eur. J. Inform. Syst. 23, 708-726. doi: 10.1057/ejis.2013.19

Peral-Peral, B., Arenas-Gaitán, J., and Villarejo-Ramos, Á. F. (2015). From digital divide to psycho-digital divide: elders and online social networks. Comunicar 23, 57-64. doi: 10.3916/C45-2015-06

Pickering, A. (2005). Decentering sociology: synthetic dyes and social theory. Perspect. Sci. 13, 352-405. doi: 10.1162/106361405774287955

Pietraß, M., and Schäffer, B. (2011). Mediengenerationen-vom kohortenvergleich zu generationsspezifischen Habitus. Bildung Generat. 323-332. doi: $10.1007 / 978-3-531-92837-1 \_26$

Reckwitz, A. (2002). Toward a theory of social practices: a development in culturalist theorizing. Eur. J. Soc. Theor. 5, 243-263. doi: $10.1177 / 13684310222225432$

Riley, M. W. E., Kahn, R. L. E., Foner, A. E., and Mack, K. A. (1994). Age and Structural Lag: Society's Failure to Provide Meaningful Opportunities in Work, Family, and Leisure. New York, NY: John Wiley and Sons.

Roosth, S., and Silbe, S. (2009). (2009). "Science and technology studies: from controversies to posthumanis social theory," in Social Theory, ed B. S. Turner (Chichester: Wiley-Blackwell).

Rosales, A., and Fernández-Ardèvol, M. (2016). "Generational comparison of simultaneous internet activities using smartphones and computers," in Paper Presented at the International Conference on Human Aspects of IT for the Aged Population (Toronto, ON).

Schäffer, B. (2003). Generation-Medien-Bildung: Medienpraxiskulturen im Generationsvergleich. Opladen: Leske+ Budrich.

Schatzki, T. R. (1996). Social Practices: A Wittgensteinian Approach to Human Activity and the Social. Cambridge: Cambridge University Press.
Schatzki, T. R. (2002). The Site of the Social: A Philosophical Account of the Constitution of Social Life and Change. University Park, PA: Pennsylvania State University Press.

Schinkel, W. (2007). Sociological discourse of the relational: the cases of Bourdieu \& Latour. Sociol. Rev. 55, 707-729. doi: 10.1111/j.1467-954X. 2007.00749.x

Schmidt, R. (2006). "Technik, Risiko und das Zusammenspiel von Habitat und Habitus," in Kalkuliertes Risiko. Technik, Spiel und Sport an der Grenze, ed G. Gebauer (Frankfurt am Main: Campus-Verlag), 78-95.

Schmidt, R. (2008). "Das Zusammenspiel von Habitat und Habitus und die Sozialität der Artefakte: zur empirischen Rekonstruktion der praktischen Logik von Programmierung und Softwareentwicklung," in Paper Presented at the Kongress Die Natur der Gesellschaft (Kassel).

Schröter, K. R. (2012). "Altersbilder als Körperbilder: doing age by bodyfication," in Individuelle und Kulturelle Altersbilder: Expertisen zum Sechsten Altenbericht der Bundesregierung, eds F. Berner, J. Rossow, and K.-P. Schwitzer (Wiesbaden: VS Verlag für Sozialwissenschaften), 153-229.

Seifert, A., and Schelling, H. R. (2016). Old and offline?: findings on the use of the Internet by people aged 65 years and older in Switzerland. Z. Gerontol. Geriatr. 49, 619-625. doi: 10.1007/s00391-015-0965-1

Selwyn, N. (2004). Reconsidering political and popular understandings of the digital divide. New Media Soc. 6, 341-362. doi: 10.1177/1461444804042519

Shove, E., Pantzar, M., and Watson, M. (2012). The Dynamics of Social Practice: Everyday Life and How It Changes. London: Sage.

Silver, M. P. (2013). Socio-economic status over the lifecourse and internet use in older adulthood. Ageing Soc. 34, 1019-1034. doi: 10.1017/S0144686X12001420

Sixsmith, A., and Gutman, G. (2013). Technologies for Active Aging, Vol. 9. New York, NY: Springer Science and Business Media.

Stengers, I. (2011). "Wondering about materialism," in The Speculative Turn: Continental Materialism and Realism, eds L. R. Bryant, N. Srnicek, and G. Harman (Melbourne, VIC: re.press), 368-381.

Sterne, J. (2003). Bourdieu, technique and technology. Cult. Stud. 17, 367-389. doi: 10.1080/0950238032000083863a

Swartz, D. L. (2013). Symbolic Power, Politics, and Intellectuals: the Political Sociology of Pierre Bourdieu. Chicago, IL: University of Chicago Press.

Tichenor, P. J., Donohue, G. A., and Olien, C. N. (1970). Mass media flow and differential growth in knowledge. Public Opin. Q. 34, 159-170. doi: $10.1086 / 267786$

Urban, M. (2017). 'This really takes it out of you!' The senses and emotions in digital health practices of the elderly. Digital Health 3, 1-16. doi: $10.1177 / 2055207617701778$

Venkatesh, V., and Bala, H. (2008). Technology acceptance model 3 and a research agenda on interventions. Decis. Sci. 39, 273-315. doi: 10.1111/j.1540-5915.2008.00192.x

Wacquant, L. (1989). Toward a reflexive sociology. A workshop with Pierre Bourdieu. Sociol. Theory 7:26. doi: 10.2307/202061

Walker, A. (1981). Towards a political economy of old age. Ageing Soc. 1, 73-94. doi: $10.1017 /$ S0144686X81000056

Williams, S. J., Higgs, P., and Katz, S. (2012). Neuroculture, active ageing and the 'older brain': problems, promises and prospects. Sociol. Health Illn. 34, 64-78. doi: 10.1111/j.1467-9566.2011.01364.x

Wittek, R., Snijders, T., and Nee, V. (2013). The Handbook of Rational Choice Social Research. Redwood City, CA: Stanford University Press.

Zillien, N., and Hargittai, E. (2009). Digital distinction: status-specific types of internet usage. Soc. Sci. Q. 90, 274-291. doi: 10.1111/j.1540-6237.2009.00617.x

Conflict of Interest Statement: The authors declare that the research was conducted in the absence of any commercial or financial relationships that could be construed as a potential conflict of interest.

Copyright (๑) 2018 Wanka and Gallistl. This is an open-access article distributed under the terms of the Creative Commons Attribution License (CC BY). The use, distribution or reproduction in other forums is permitted, provided the original author(s) and the copyright owner are credited and that the original publication in this journal is cited, in accordance with accepted academic practice. No use, distribution or reproduction is permitted which does not comply with these terms. 